\title{
African Neurosurgery Research: A Scientometric Analysis of the Top 115 Most Cited Articles
}

Ulrick Sidney Kanmounye ( $\square$ ulricksidney@gmail.com )

Association of Future African Neurosurgeons https://orcid.org/0000-0001-6791-1018

Stéphane Nguembu

Université des Montagnes: Universite des Montagnes

Yvan Zolo

University of Buea Faculty of Health Sciences

Dawin Sichimba

The Copperbelt University School of Medicine

Myron L. Rolle

Massachusetts General Hospital

Adam Ammar

Montefiore Hospital and Medical Center: Montefiore Medical Center

Nourou Dine Adeniran Bankole

Mohammed V University of Rabat: Universite Mohammed V de Rabat

Kantenga DM Kabulo

Université de Lubumbashi: Universite de Lubumbashi

Beverly Cheserem

Aga Khan Hospital Mombasa

Kee B. Park

Harvard Medical School

Claire Karekezi

Rwanda Military Hospital

Ignatius Esene

University of Bamenda

Research

Keywords: Africa, bibliometrics, neurosurgery, scientometrics, research

Posted Date: June 2nd, 2021

DOI: https://doi.org/10.21203/rs.3.rs-564592/v1

License: @ (1) This work is licensed under a Creative Commons Attribution 4.0 International License. Read Full License 


\section{Abstract}

\section{Background}

The use of quantitative and qualitative scientometrics provides deductive and inductive insights into the landscape of research in a specific area. In this manuscript, the authors identified the major contributors of African neurosurgery and emerging terms.

\section{Methods}

Articles on African neurosurgery were searched on Web of Science and 8 other repositories without language or date restrictions. The $\mathrm{H}$-index, co-author, author country, time trend, and keyword analyses were done using Bibexcel and VOSviewer.

\section{Results}

115 articles on African neurosurgery were published in 36 journals by 90 first authors. The journals with the most articles were World Neurosurgery (46, $40.0 \%)$, Journal of Neurosurgery Pediatrics (8, 7.0\%), and Neurosurgery $(7,6.1 \%)$. There was a rapid increase in the number of articles from 2010 and the median number of citations was 8 (IQR: 4-16). Qureshi MM had the highest H-index score (6) while Warf BC (5, 4.3\%), Adeleye AO (4, 3.5\%), and El Khamlichi $(4,3.5 \%)$ contributed the most to the 115 articles. The articles by Lanzino G (1999), Warf BC (2011), and Warf BC (2005) were the most influential. The U.S.A. had the largest node and South Africa, Kenya and Uganda were the most impactful African countries. Pediatric neurosurgery dominated the keywords and global neurosurgery was an emerging term.

\section{Conclusion}

The most cited articles on African neurosurgery are published in prestigious specialty journals and neurosurgeons from Southern and East Africa are the most impactful local researchers. Future research should analyze the differences between African regions.

\section{Background}

African neurosurgery has grown significantly over the past two decades. The number of training programs, international collaborations, specialist African neurosurgeons, and research output have all increased at more than three fold.[1-5] The unique African context warrants innovations and the implementation of contextually-aware interventions. Such interventions require locally-sourced data and the contribution of local neurosurgeons. It is not enough for local researchers to publish articles because publication does not necessarily translate to dissemination, citation, and implementation of study findings.

Scholarly impact and dissemination is commonly evaluated using the H-index, a scientometric measure that takes into account productivity and citations. The $\mathrm{H}$-index score is correlated with academic rank, experience, and having additional graduate degrees.[6, 7] Higher H-index scores confer prestige to neurosurgeons and academic institutions leading to greater patient volumes, increased interest from prospective trainees, and prospective faculty.[8-10]

The qualitative evaluation of academic output gets less attention than quantitative scientometrics. Qualitative scientometrics finds patterns between authors, co-authors, citations, and keywords. These analyses help identify key actors and emerging themes in a field. On the other hand, quantitative scientometrics measures the strengths of interactions and influence of articles, authors, and keywords. Together, qualitative and quantitative scientometrics provide a deductive and an inductive overview of the current research landscape and its evolution.[11] Hence, both types of scientometrics are complementary.

The impact and stakeholders of African neurosurgery research have not been evaluated before. In this scientometric analysis, we set out to identify the major contributors of African neurosurgery research and to identify key terms.

\section{Methods}

Articles on African neurosurgery were searched on Web of Science Core Collection, Arabic Citation Index, Russian Science Citation Index, Chinese Science Citation Database, Data Citation Index, BIOSIS Citation Index, and SciELO Citation Index without language or date restrictions (from inception to April 24, 2020). These databases were chosen because they offer comprehensive backward and forward citation data, unlike other major databases (PubMed, Embase, or CINAHL). The search strategy is available in the Supplemental file. Two authors (USK and YZ) carried out the title and abstract screening and isolated African neurosurgery articles with at least 2 citations - the search yielded 115 articles. These articles and their metadata (author names, author affiliations, article title, journal, publication year, number of citations, and references) were then imported as a text file into BibExcel (BibExcel, Austria). The text file was equally imported into VOSViewer (Center for Science and Technology Studies, University of Leiden, Netherlands). The bibliometric analyses consisted in citation, co-citation, keyword, author affiliation, and h-index calculations. When possible, the bibliometric analyses were visualized with VOSViewer. The authors set an occurrence threshold for each visualization: document analysis (2), co-authorship (2), country (2), and keywords (5). The keywords were extracted from the titles and abstracts, and the authors chose binary counting. The methodologies for these analyses have been described in previous articles. $[12,13]$

\section{Results}

\section{Descriptive scientometrics}

The 115 articles on African neurosurgery were published in 36 journals by 90 first authors and African researchers were the first authors of 61 ( $53.0 \%$ ) articles. African neurosurgery articles were published in World Neurosurgery (Ex-Surgical Neurology) (46, 40.0\%), Journal of Neurosurgery Pediatrics (8, $7.0 \%)$, and 
Neurosurgery (7, 6.1\%). Of note, 10 (8.7\%) articles were published in African journals: South African Medical Journal (4 articles, 3.5\%), Nigerian Journal of Clinical Practice (2 articles, 1.7\%), East African Medical Journal (1 article, 0.9\%), Pan African Medical Journal (1 article, $0.9 \%)$, SA Journal of Radiology (1 article, $0.9 \%$ ), and South African Journal of Surgery (1 article, $0.9 \%)$.

2010 was an index year because most $(86,74.8 \%)$ articles were published on this date or later. The 61 articles by local researchers were published between 1974 and 2020 (median = 2011) and most were published in 7 journals: World Neurosurgery (Ex-Surgical Neurology) (13, 21.3\%), Neurosurgery (6, 9.8\%), South African Medical Journal (4, 6.6\%), Neurochirurgie (3, 4.9\%), Child Nervous System (3, 4.9\%), Journal of Neurosurgery - Pediatrics (3, 4.9\%), and Journal of Neurosciences in Rural practice $(3,4.9 \%)$.

The median number of citations by African neurosurgery articles was 8 (IQR: 4-16) and the articles by local researchers had a median of 6 citations (IQR=244.5). Also, the median article usage count recorded since 2013 was 2 (IQR: 1-3).

The first authors with the most articles were Warf BC (5, 4.3\%), Adeleye AO (4,3.5\%), El Khamlichi (4, 3.5\%), Nathoo N (3, 2.6\%), and Park BE (3, 2.6\%) (Supplemental file). Qureshi MM (6), Haglund MM (5), Warf BC (5), El Khamlichi A (5), Piquer J(5), Hartl R (5), and Muhumuza M (5) had the highest H-index scores among the most cited authors of African neurosurgery articles (Table 1).

Table 1. Author H-index score calculated from the top 115 most cited African neurosurgery articles. Only authors with a H-index $\geq 3$ are shown.

\begin{tabular}{|c|c|c|c|c|}
\hline Author & H-index & Citation sum within $\mathrm{H}$-core & All citations & All articles \\
\hline Qureshi MM & 6 & 89 & 105 & 9 \\
\hline Haglund MM & 5 & 132 & 139 & 7 \\
\hline Warf BC & 5 & 217 & 221 & 6 \\
\hline El Khamlichi A & 5 & 98 & 103 & 7 \\
\hline Piquer J & 5 & 61 & 65 & 6 \\
\hline Hartl R & 5 & 51 & 60 & 8 \\
\hline Muhumuza M & 5 & 121 & 124 & 6 \\
\hline Kiryabwire J & 4 & 115 & 118 & 5 \\
\hline Santos MM & 4 & 27 & 27 & 4 \\
\hline Ellegala DB & 4 & 48 & 48 & 4 \\
\hline Zubkov MR & 4 & 27 & 27 & 4 \\
\hline Young $\mathrm{PH}$ & 4 & 51 & 51 & 4 \\
\hline Nathoo N & 4 & 158 & 161 & 5 \\
\hline Nadvi SS & 4 & 154 & 154 & 4 \\
\hline Smith ER & 3 & 34 & 34 & 3 \\
\hline Ssenyonjo H & 3 & 27 & 27 & 3 \\
\hline Budohoski KP & 3 & 20 & 20 & 3 \\
\hline Scholler K & 3 & 20 & 20 & 3 \\
\hline Dempsey RJ & 3 & 44 & 44 & 3 \\
\hline Shabani HK & 3 & 20 & 23 & 4 \\
\hline Abdelgadir $\mathrm{J}$ & 3 & 35 & 35 & 3 \\
\hline Mangat HS & 3 & 20 & 20 & 3 \\
\hline Ngerageza JG & 3 & 20 & 22 & 4 \\
\hline Mukasa J & 3 & 58 & 61 & 4 \\
\hline Mayegga $\mathrm{E}$ & 3 & 40 & 40 & 3 \\
\hline Nicholas J & 3 & 27 & 27 & 3 \\
\hline Park BE & 3 & 19 & 19 & 3 \\
\hline Fuller A & 3 & 25 & 25 & 3 \\
\hline Kucia EJ & 3 & 25 & 25 & 3 \\
\hline Haglund M & 3 & 30 & 30 & 3 \\
\hline Albright AL & 3 & 40 & 40 & 3 \\
\hline Adeleye AO & 3 & 13 & 16 & 4 \\
\hline
\end{tabular}

Page 3/10 


\section{Visualization}

Bibliographic coupling of documents revealed 7 clusters composed of 91 articles and 789 links. The total link strength was 1658 and the largest clusters were organized around Lanzino G (1999), Warf BC (2011), and Warf BC (2005). The authors with the most nodes among the large clusters were El Khamlichi A (3) and Warf BC (2) (Figure 1).

There were 5 clusters in the co-authorship analysis that had 44 items connected by 191 links. The co-authorship clusters were primarily made up of researchers working in East Africa and the total link strength was 329 (Figure 2).

The map of author affiliations (by country) revealed 5 clusters constituted by 30 items with 150 links and a total link strength of 228 . The United States of America had the largest node and the highest number of links with other countries. South Africa, Kenya, and Uganda had the largest nodes among African countries (Figure 3).

South Africa (22, 19.1\%), Kenya (19, 16.5\%), and Tanzania (16, 13.9\%) contributed the most articles. Also, Kenya (33), Tanzania (33), and Uganda (25) had the strongest links among the African countries (Table 2).

Table 2. Total link strength of the most-cited African neurosurgery articles.

\begin{tabular}{|llll|}
\hline Country & Number of articles & Total citations & Total link strength \\
\hline South Africa & 22 & 345 & 7 \\
Kenya & 19 & 198 & 33 \\
Tanzania & 16 & 134 & 33 \\
Uganda & 11 & 225 & 25 \\
Nigeria & 10 & 54 & 1 \\
Morocco & 7 & 103 & 15 \\
Rwanda & 3 & 12 & 15 \\
Burkina Faso & 2 & 5 & 14 \\
Cameroon & 2 & 4 & 15 \\
DR Congo & 2 & 6 & 15 \\
Egypt & 2 & 24 & 0 \\
Ethiopia & 2 & 5 & 3 \\
Malawi & 2 & 17 & 2 \\
Benin & 1 & 2 & 14 \\
Gabon & 1 & 6 & 14 \\
Guinea & 1 & 2 & 14 \\
Mali & 1 & 2 & 0 \\
Mauritania & 1 & 2 & 14 \\
Niger & 1 & 2 & 14 \\
Republic of Congo & 14 & \\
Togo & 1 & 2 & 14 \\
Zimbabwe & 1 & 2 & 14 \\
\hline
\end{tabular}

The keywords of the African neurosurgery publications were organized in 3 clusters. These clusters were composed of 32 items in a 312 -link network. The keyword network had a total link strength of 877 and the largest nodes were "Africa”, "Neurosurgery", "Sub-Saharan Africa", and "Hydrocephalus" (Figure 4).

\section{Discussion}

This is the first comprehensive scientometric analysis of African neurosurgery research. 90 authors contributed to the 115 articles and the greatest first authorcontributors were Warf BC, Adeleye AO, and El Khamlichi. Qureshi MM was the most impactful first author $(\mathrm{H}$-index score $=6)$ and the articles by Lanzino $\mathrm{G}$ (1999), Warf BC (2011), and Warf BC (2005) had the greatest number of relationships. Interestingly, the U.S.A. had the largest node among author country affiliations while South Africa, Kenya, and Uganda were the most impactful African countries. The U.S.A.'s position is probably due to the numerous research collaborations between American and African academic centers. Some of these collaborations include Duke University in Uganda, Weill-Cornell University in Tanzania, and CURE in Uganda.[4, 14, 15] 
Unlike Southern and East Africa, West and Central Africa were underrepresented. A potential reason for this could be the language barrier. The majority of countries in West and Central Africa are francophone.[16] If authors in these countries publish primarily in French speaking journals it might explain why their articles are less cited. This hypothesis is supported by Akhaddar's review of African neurosurgery articles on PubMed that found that French speaking countries in West and Central Africa had low scholarly outputs.[17] Let us note however that the contributions of France, Canada, Morocco, and Switzerland to the most cited articles on African neurosurgery does not support the language barrier hypothesis.

Another avenue to explore is the post-publication practices of researchers. There are numerous ways to increase the visibility of an article in the postpublication phase. One of the most effective ways is non-scientific communication.[18, 19] Future studies should explore the landscape of neurosurgery publication in these regions. Moreover, a comparative analysis of more versus less impactful African regions might help tease out the differences.

The sharing of resources and expertise appears to be greater between African countries and non-African countries than it is between African countries. This can be appreciated in the co-author and author country analyses. The discrepancy between African regions and limited links are signs of the lack of research collaborations between African countries. Researchers from less productive regions stand to gain if they collaborate with their colleagues from more productive regions.

\section{Journal analysis}

The top three journals were World Neurosurgery (40.0\%), Journal of Neurosurgery - Pediatrics (7.0\%), and Neurosurgery (6.1\%). These three journals are some of the most prestigious journals in this field.[20] World Neurosurgery's first position is understandable given that it has a more diverse readership and a specific section for neurosurgeons with low-resource settings (Doing more with less).[21] On the other hand, the ranking of the Journal of Neurosurgery Pediatrics can be explained by the contribution of the Warf BC et al. Ben Warf and colleagues have contributed substantially to the development of alternative treatments of hydrocephalus (Endoscopic third ventriculostomy and choroid plexus cauterization).[22] The development of endoscopic third ventriculostomy has been a paradigm shift in the management of hydrocephalus and this is evidenced by the number of publications and their impact but also by the presence of pediatric terms in the keyword analysis. The contributions of local authors to these three journals should equally be highlighted. Generally, African first-author researchers contributed less than foreign researchers to the articles in the three prestigious journals: World Neurosurgery (Ex-Surgical Neurology) (13 of $46,28.6 \%$ ), Journal of Neurosurgery - Pediatrics (3 of $8,37.5 \%$ ), and Neurosurgery ( 6 of 7, 85.7\%). Hedt-Gauthier et al.[23] had similar findings - $68.3 \%$ of global health research in Africa is published by foreign researchers. The predominance of foreign first authors in African research has been attributed to greater technical expertise, experience, funding, and decision power.[23-26] Research collaborations between foreign and African academic institutions should be mindful of the disparities between both parties and they should design strategies to minimize these disparities. For example, research collaborations should incorporate research capacity building activities with specific and realistic milestones (study design, grant applications, project management, abstract presentations at international conferences, and first author publications).

Six of the 36 (16.7\%) journals were African, half were South African, and none of them were specialty journals. The low number of African journals is a cause of concern. We posit that the low African representation might be due to a lower proportion of African journals registered to Web of Science and a greater proportion of manuscripts being submitted to non-African journals given that non-African journals tend to have higher impact factors.[20] African journals can increase their impact factors and therefore their contribution to African neurosurgery if they publish quality papers, publish open access, and if they provide post-publication communication services.[27]

Researchers can help African journals in each of these aspects. First, researchers can help improve the quality of articles in African journals as authors and as reviewers. As authors, researchers have a duty to conduct ethically and scientifically sound research. As reviewers of African journals, researchers can screen scientifically dubious articles and give constructive feedback to the authors of less robust studies.[28] Moreover, authors can choose to publish in open access journals. We note however that most open access models require payment from the authors [29] and this can be prohibitive for researchers from low-resource settings. Fortunately, an increasing number of funders are setting aside funds for open access publication in their grants.[30] For authors without funding, they can target open access journals that do not require payment from the authors.[31] Thirdly, authors have a crucial role to play in non-scientific post-publication communication of their articles. By using visual abstracts on social media, op-eds in new media, and communications in traditional media, authors increase the visibility and impact of their research.[19, 30, 32, 33]

\section{Trend and emerging terms}

It is noteworthy that the number of top cited articles increased rapidly since 2010. This increase has happened concomitantly with the emancipation of global neurosurgery.[34] We can see from the keyword analysis that global neurosurgery is an emerging term in African neurosurgery. This finding revives the debate on the definition of global neurosurgery and supports the widely held notion that global health and neurosurgery are focused on health inequities in low- and middle-income countries; ignoring the heterogeneity in access to care within high-income countries.[35] Moreover, it can alter the perception of local experts and distract them from important debates and problems.[36] In the case of Africa, this view of global neurosurgery might divert research away from the continental research agenda and influence collaborations between local and foreign academic institutions. For example as a result of earmarked grant funds and tailoring of articles to suit high-impact factor journals, local neurosurgeons might choose to study contextually-relevant topics.

Another possible explanation for the increasing number of highly-cited articles is the establishment in the early 2010 s of partnerships between academic institutions from the U.S.A. and African institutions.[37, 38] 
We acknowledge the following limitation to our study. Our search was limited to the Web of Science database and could have constituted a bias against articles that are not referenced in this database. To curtail this bias we reported both Web of Science citations and citations from 8 other sources such as the Chinese and Russian.

\section{Conclusions}

The most cited articles on African neurosurgery are published in the most prestigious specialty journals and mostly by foreign first authors. Researchers from the U.S.A. play a major role in publications from the region. African neurosurgeons and journals should increase their article visibility to increase the impact of their research. Our study highlighted an increase in the number of impactful articles and the need for more research from West and Central African countries and the need for collaboration between African researchers. Future studies should compare the research practices of African neurosurgeons so as to identify the mechanisms adopted by high performers that can be replicated in lower performing regions.

\section{Declarations}

Ethics approval and consent to participate

Not applicable.

Consent for publication

Not applicable

Availability of data and materials

The datasets used and/or analyzed during the current study are available from the corresponding author on reasonable request.

\section{Competing interests}

The authors declare that they have no competing interests.

Funding

Not applicable

Authors' contributions

USK conceptualized the study, investigated, curated, analyzed, and visualized the data, wrote the original draft of the manuscript, and administered the project. SN, YZ, DS, MLR, AA, NDAB, KDMK, BC, KBP, CK, and IE investigated, validated, and wrote the original manuscript draft. All authors have read and approved the manuscript.

\section{References}

1. Karekezi C, El Khamlichi A. Takeoff of African Neurosurgery and the World Federation of Neurosurgical Societies Rabat Training Center Alumni. World Neurosurg. 2019;126:576-80.

2. Leidinger A, Extremera P, Kim EE, Qureshi MM, Young PH, Piquer J. The challenges and opportunities of global neurosurgery in East Africa: the Neurosurgery Education and Development model. Neurosurg Focus. 2018;45:E8.

3. Uche EO, Mezue WC, Ajuzieogu O, Amah CC, Onyia E, lloabachie I, et al. Improving capacity and access to neurosurgery in sub-Saharan Africa using a twinning paradigm pioneered by the Swedish African Neurosurgical Collaboration. Acta Neurochir (Wien). 2020;162:973-81.

4. Haglund MM, Fuller AT. Global neurosurgery: innovators, strategies, and the way forward: JNSPG 75th Anniversary Invited Review Article. J Neurosurg. 2019;131:993-9.

5. Kanmounye US, Lartigue JW, Sadler S, Yuki Ip HK, Corley J, Arraez MA, et al. Emerging Trends in the Neurosurgical Workforce of Low- and Middle-Income Countries: A cross-sectional study. World Neurosurg; 2020

6. Lee JS, Kraus KL, Couldwell WT. Use of the h index in neurosurgery. Clinical article. J Neurosurg. 2009.

7. Keough MB, Newell C, Rheaume AR, Sankar T. Association between graduate degrees and publication productivity in academic neurosurgery. Can J Neurol Sci J Can Sci Neurol. 2020;:1-27.

8. Samuel N, Shamji MF, Bernstein M. Neurosurgical patients' perceptions of the "surgeon+": a qualitative study. J Neurosurg. 2016;124:849-53.

9. Marasa LH, Pittman TA. Factors neurosurgery candidates use when choosing a residency program. J Neurosurg. 2014;120:167-72.

10. Bean JR. Ambition. Predicting and Pursuing an Academic Neurosurgical Career. World Neurosurg. 2017;101:766-7.

11. Biscaro C, Giupponi C. Co-authorship and bibliographic coupling network effects on citations. PloS One. 2014;9:e99502.

12. Persson O, Danell R, Wiborg J. Celebrating scholarly communication studies: A Festschrift for Olle Persson at his 60th Birthday. 2009.

https://portal.research.lu.se/ws/files/5902071/1458992.pdf. Accessed 8 Jun 2020.

13. van Eck NJ, Waltman L. Citation-based clustering of publications using CitNetExplorer and VoSviewer. Scientometrics. 2017;111:1053-70.

Page 6/10 
14. Budohoski KP, Ngerageza JG, Austard B, Fuller A, Galler R, Haglund M, et al. Neurosurgery in East Africa: Innovations. World Neurosurg. $2018 ; 113: 436-52$.

15. Ssenyonga LN, Leonard AL, Coetzee M. Articulating the paediatric neurosurgical nursing practice model of care at CURE children's hospital of uganda: Challenging current thought with emerging evidence. Childs Nerv Syst. 2016;32:2027.

16. World Bank Group. Open Data. The World Bank - Data. 2020. https://data-worldbank-org.ezp-prod1.hul.harvard.edu/. Accessed 7 Apr 2020.

17. Akhaddar A. African Contribution to the World Neurosurgical Literature During the Past Two Decades (1999-2018) Using PubMed Database. World Neurosurg. 2019;126:314-21.

18. Ibrahim AM. Seeing is Believing: Using Visual Abstracts to Disseminate Scientific Research. Am J Gastroenterol. 2018;113:459-61.

19. Ibrahim A, Abbass M, Anderson P, Berger R, Dimick J, Harris C, et al. Use of a Visual Abstract to Disseminate Scientific Research. 2018. https://static1.squarespace.com/static/5854aaa044024321a353bb0d/t/5a527aa89140b76bbfb2028a/1515354827682/VisualAbstract_Primer_v4_1.pdt Accessed 1 Apr 2020.

20. Madhugiri VS, Ambekar S, Strom SF, Nanda A. A technique to identify core journals for neurosurgery using citation scatter analysis and the Bradford distribution across neurosurgery journals: A review. J Neurosurg. 2013;119:1274-87.

21. Benzel EC. World Neurosurgery - About. World Neurosurgery. 2015. https://www.journals.elsevier.com/world-neurosurgery. Accessed 11 Jun 2020.

22. Warf BC. The Impact of Combined Endoscopic Third Ventriculostomy and Choroid Plexus Cauterization on the Management of Pediatric Hydrocephalus in Developing Countries. World Neurosurg. 2013;79:S23.e13-S23.e15.

23. Hedt-Gauthier BL, Jeufack HM, Neufeld NH, Alem A, Sauer S, Odhiambo J, et al. Stuck in the middle: a systematic review of authorship in collaborative health research in Africa, 2014-2016. BMJ Glob Health. 2019;4:e001853.

24. Tarkang EE, Bain LE. The bane of publishing a research article in international journals by African researchers, the peer-review process and the contentious issue of predatory journals: a commentary. Pan Afr Med J. 2019;32. doi:10.11604/pamj.2019.32.119.18351.

25. Dhalla KA, Guirguis M. Barriers and incentives for conducting research amongst the ophthalmologists in Sub-Sahara Africa. PLOS ONE. 2018;13:e0197945.

26. Davies J, Mullan Z. Research capacity in Africa-will the sun rise again? Lancet Glob Health. 2016;4:e287.

27. Uzun C. Increasing the Impact Factor in the Ethical Way. Balk Med J. 2017;34:482-4.

28. Kelly J, Sadeghieh T, Adeli K. Peer Review in Scientific Publications: Benefits, Critiques, \& A Survival Guide. EJIFCC. 2014;25:227-43.

29. Solomon D, Björk B-C. Article processing charges for open access publication-the situation for research intensive universities in the USA and Canada. PeerJ. 2016;4. doi:10.7717/peerj.2264.

30. Brink PA. Article visibility: journal impact factor and availability of full text in PubMed Central and open access. Cardiovasc J Afr. 2013;24:295-6.

31. DOAJ. Directory of Open Access Journals. https://doaj.org. Accessed 20 May 2020.

32. Lindquist LA, Ramirez-Zohfeld V. Visual Abstracts to Disseminate Geriatrics Research Through Social Media. J Am Geriatr Soc. 2019;67:1128-31.

33. Teoh JY-C, Mackenzie G, Tortolero L, Rivas JG. Social Media Analytics: What You Need to Know as a Urologist. Eur Urol Focus. 2020;6:434-6.

34. Park K. WFNS Global Neurosurgery Committee. Global Neurosurgery. 2019. https://globalneurosurgery.org/. Accessed 3 Jan 2020.

35. Andrews RJ. What's in a Name? "Global Neurosurgery" in the 21st Century. World Neurosurg. 2020;143:336-8.

36. Abimbola S. The foreign gaze: authorship in academic global health. BMJ Glob Health. 2019;4:e002068.

37. Haglund MM, Warf B, Fuller A, Freischlag K, Muhumuza M, Ssenyonjo H, et al. Past, Present, and Future of Neurosurgery in Uganda. Neurosurgery. 2017;80:656-61.

38. Leidinger A, Extremera P, Kim EE, Qureshi MM, Young PH, Piquer J. The challenges and opportunities of global neurosurgery in East Africa: the Neurosurgery Education and Development model. Neurosurg Focus. 2018;45:E8.

\section{Figures}




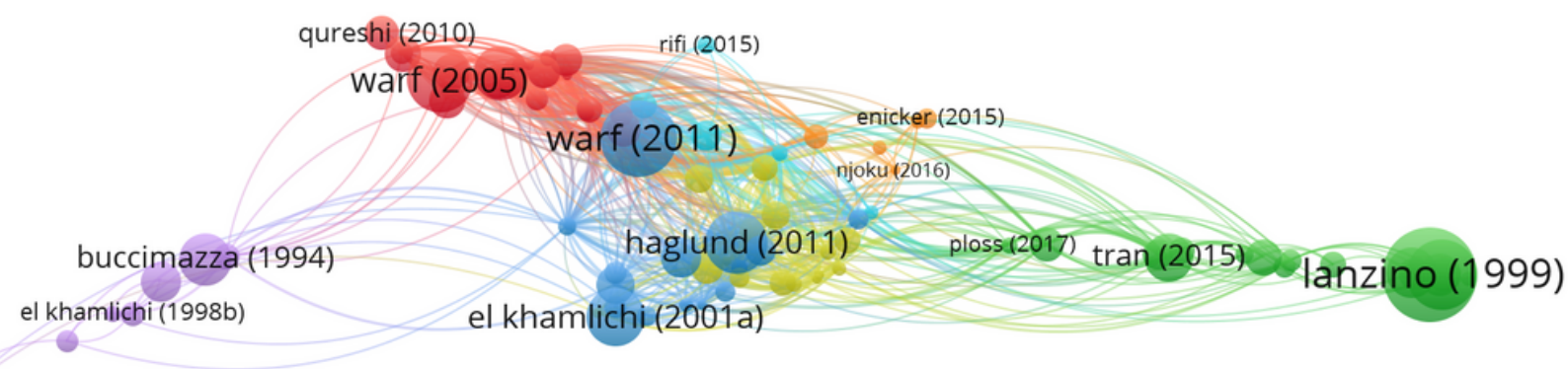

el khamlichi (2001b)

\section{\& VOSviewer}

\section{Figure 1}

Visualization of bibliographic coupling by document. Each circle (node) indicates an article, the size of the nodes indicates the activity of the article. The distance between two nodes is inversely proportional to the number of co-citations; shorter distances indicate higher numbers of co-citations. Nodes with the same color are related.

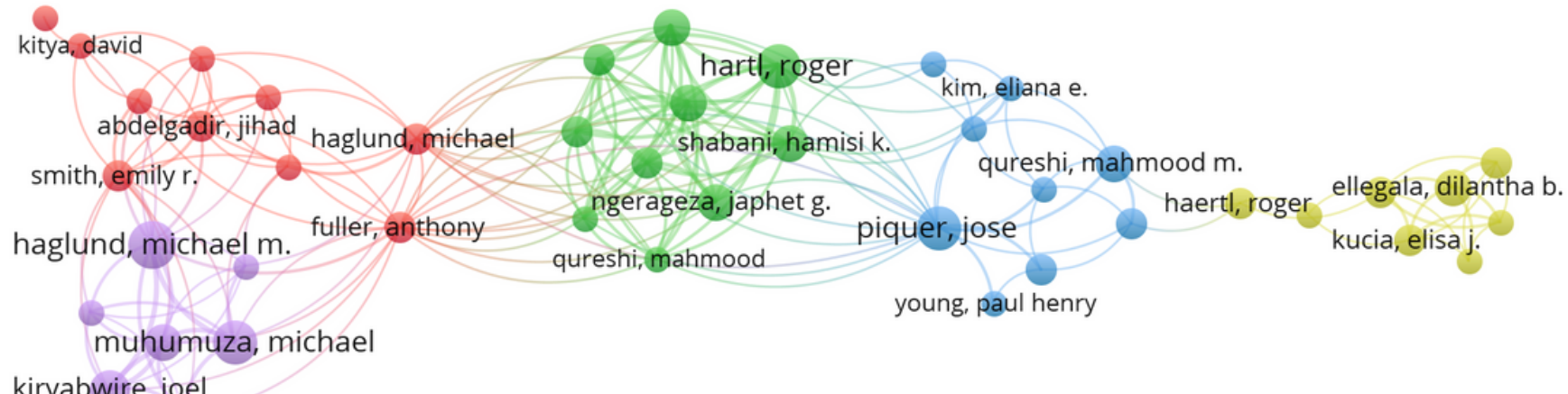

kiryabwire, joel

\& Vosviewer

Figure 2 
African neurosurgery co-authorship link visualization. Each circle (node) represents a co-author, the size of the nodes indicates the activity of the co-author. The closer two nodes are the more they are related. Nodes with the same color are related.

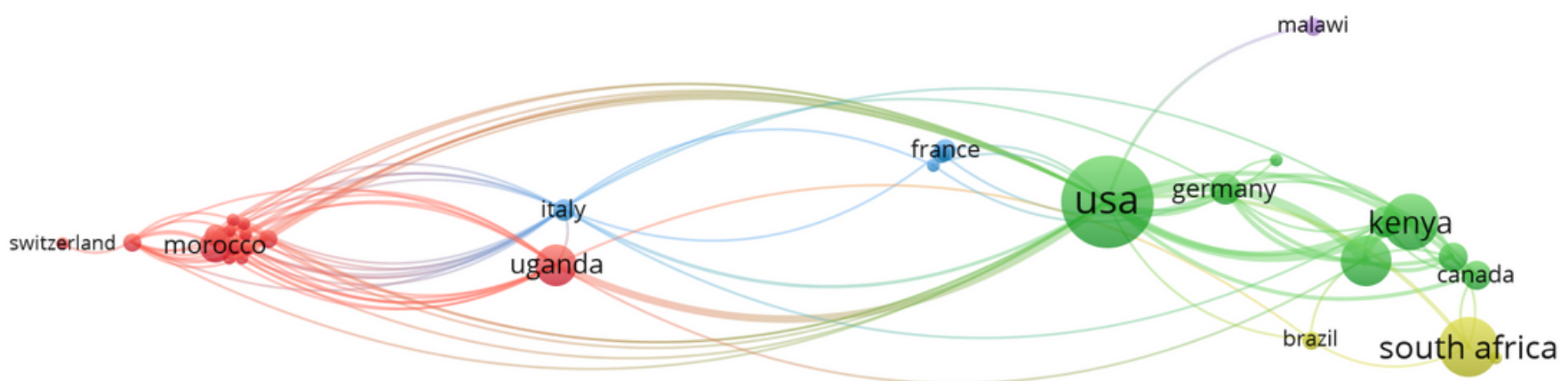

\section{\& VOSviewer}

\section{Figure 3}

Visualization of author affiliations by country. Each circle (node) represents a country, the size of the nodes indicates the activity of the country. The closer two nodes are the more they are related. Nodes with the same color are related. 


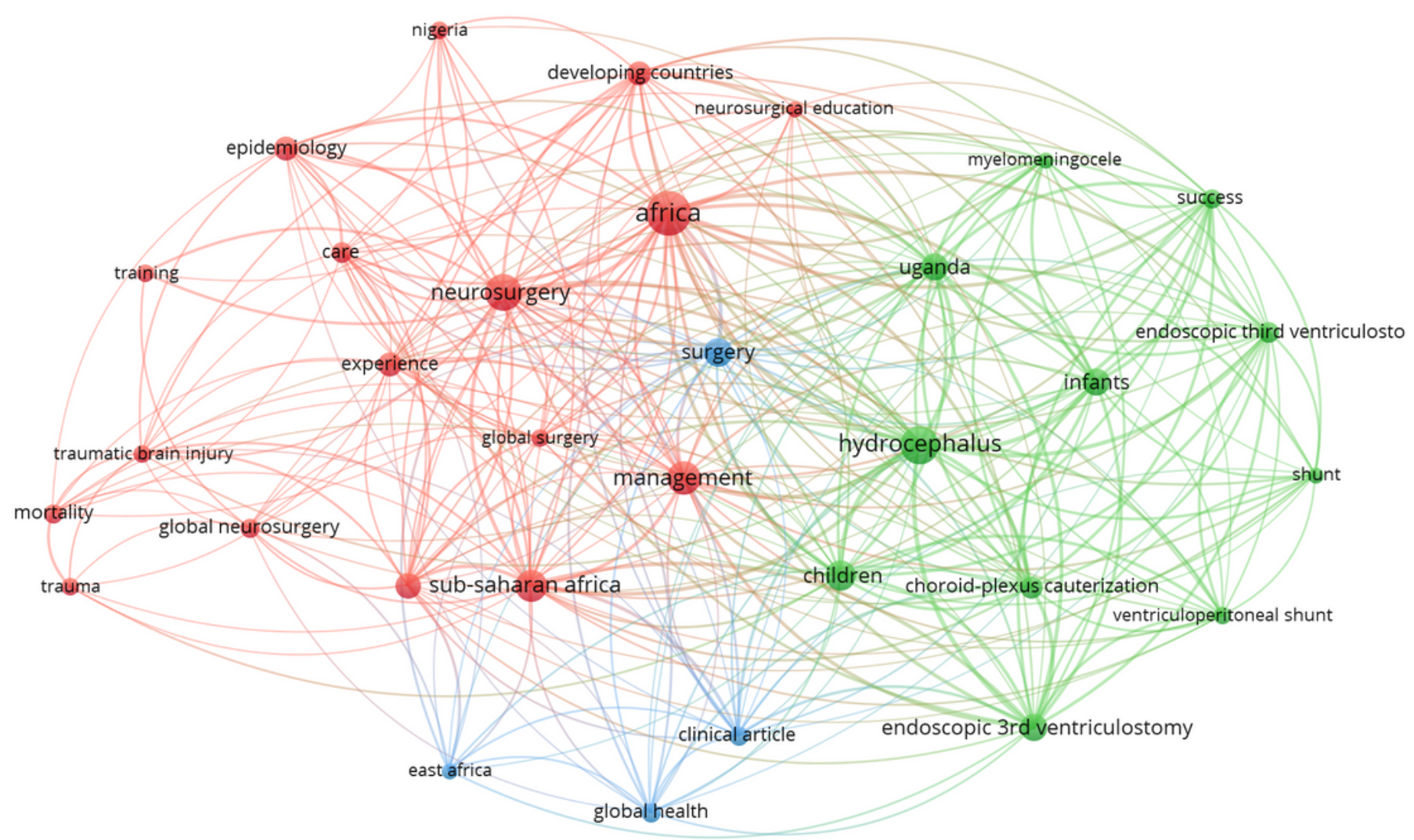

Figure 4

African neurosurgery keyword visualization. Each circle (node) represents a keyword, the size of the nodes indicates the activity of the keyword. The closer two nodes are, the more they are related. Nodes with the same color are related.

\section{Supplementary Files}

This is a list of supplementary files associated with this preprint. Click to download.

- SupplementalFile1Partll.docx

- SupplementalFile2Partll.docx

- SupplementalFile3Partll.docx 